\title{
Diagnostic Significance of Cortical Superficial Siderosis for Alzheimer Disease in Patients with Cognitive Impairment
}

Y. Inoue, M. Nakajima, H. Uetani, DT. Hirai, M. Ueda, M. Kitajima, D. Utsunomiya, M. Watanabe, M. Hashimoto, M. Ikeda, Y. Yamashita, and Y. Ando

\begin{abstract}
BACKGROUND AND PURPOSE: Because the diagnostic significance of cortical superficial siderosis for Alzheimer disease and the association between cortical superficial siderosis and the topographic distribution of cerebral microbleeds have been unclear, we investigated the association between cortical superficial siderosis and clinicoradiologic characteristics of patients with cognitive impairment.
\end{abstract}

MATERIALS AND METHODS: We studied 347 patients (217 women, 130 men; mean age, $74 \pm 9$ years) who visited our memory clinic and underwent MR imaging (3T SWI). We analyzed the association between cortical superficial siderosis and the topographic distribution of cerebral microbleeds plus clinical characteristics including types of dementia. We used multivariate logistic regression analysis to determine the diagnostic significance of cortical superficial siderosis for Alzheimer disease.

RESULTS: Twelve patients (3.5\%) manifested cortical superficial siderosis. They were older $(P=.026)$ and had strictly lobar cerebral microbleeds significantly more often than did patients without cortical superficial siderosis ( $50.0 \%$ versus $19.4 \%, P=.02)$; the occurrence of strictly deep and mixed cerebral microbleeds, however, did not differ in the 2 groups. Alzheimer disease was diagnosed in 162 (46.7\%) patients. Of these, 8 patients (4.9\%) had cortical superficial siderosis. In the multivariate logistic regression analysis for the diagnosis of Alzheimer disease, lacunar infarcts were negatively and independently associated with Alzheimer disease $(P=.007)$.

CONCLUSIONS: Although cortical superficial siderosis was associated with a strictly lobar cerebral microbleed location, it was not independently associated with Alzheimer disease in a memory clinic setting. Additional studies are required to investigate the temporal changes of these cerebral amyloid angiopathy-related MR imaging findings.

ABBREVIATIONS: $\mathrm{AD}=$ Alzheimer disease; $\mathrm{CAA}=$ cerebral amyloid angiopathy; $\mathrm{cSS}=$ cortical superficial siderosis; $\mathrm{DLB}=$ dementia with Lewy bodies; $\mathrm{MBs}=$ cerebral microbleeds; $\mathrm{MCl}=$ mild cognitive impairment

$\mathbf{C}_{\mathrm{p}}^{\circ}$ ortical superficial siderosis (cSS) is characterized by linear hypointensities on the surface of cerebral cortex gyri on $\mathrm{T}^{*}$ weighted gradient-echo MR imaging or SWI. ${ }^{1,2}$ cSS reflects subtle hemorrhages from amyloid-affected fragile cortical or leptomeningeal vessels and occurs often in patients with cerebral amyloid angiopathy (CAA); associations of cSS with repeat lobar hemorrhages have been reported. ${ }^{3-5}$ Several studies showed that patients with cognitive impairment manifested a higher prevalence of cSS compared with the general population. ${ }^{6,7}$ cSS, along with lobar cerebral microbleeds

Received January 12, 2015; accepted after revision June 18.

From the Departments of Neurology (Y.I., M.N., M.U., M.W., Y.A.), Diagnostic Radiology (H.U., T.H., M.K., D.U., Y.Y.), and Psychiatry and Neuropathobiology (M.H., M.I.), Graduate School of Medical Sciences, Kumamoto University, Kumamoto, Japan.

Please address correspondence to Yasuteru Inoue, MD, Department of Neurology, Graduate School of Medical Sciences, Kumamoto University, 1-1-1 Honjo, Kumamoto 860-8556, Japan; e-mail: yinoue@fc.kuh.kumamoto-u.ac.jp

三 Indicates article with supplemental on-line table.

http://dx.doi.org/10.3174/ajnr.A4496
(MBs), was described as a characteristic neuroimaging marker of CAA. $^{8,9}$

Alzheimer disease $(\mathrm{AD})$ is the most common cause of dementia in the elderly, and CAA is assumed to have a pivotal function in the underlying pathogenesis of $\mathrm{AD} .{ }^{10}$ In the aforementioned studies, cSS was associated with the presence of $\mathrm{MBs}$, and the authors speculated that a relatively high prevalence of $\mathrm{cSS}$ in patients with $\mathrm{AD}$ indicates this pathogenesis. ${ }^{6,7}$ We therefore hypothesized that cSS itself may be a significant diagnostic marker of $\mathrm{AD}$ and that lobar MBs would be observed more frequently in patients with cSS than in patients without cSS.

The primary aim of the present study was thus to clarify the diagnostic significance of cSS for $\mathrm{AD}$, with the secondary aim being to explore the radiologic markers of small-vessel disease in relation to cSS in patients with cognitive impairment.

\section{MATERIALS AND METHODS Study Population}

This study consisted of a subanalysis of a prospective clinicoradiologic study described previously. ${ }^{11}$ Consecutive patients who 
attended the Dementia Clinic of the Department of Neuropsychiatry, Kumamoto University Hospital, were recruited prospectively from January 2008 to February 2010. The Ethics Committee of Kumamoto University Hospital approved this study. The patients received information about the purpose and method of the study, and written informed consent for participation in the study was obtained from them or their caregivers.

Patients with cognitive impairment associated with posttraumatic brain injury, brain tumor, idiopathic normal pressure hydrocephalus, history of psychiatric diseases or substance abuse, and neurodegenerative diseases, including Pick disease, corticobasal degeneration, and spinocerebellar degeneration, were excluded from this study. Patients whose MR images had severe motion artifacts and patients who did not provide informed consent were also excluded.

All patients received independent neuropsychological evaluations conducted by 2 neuropsychiatrists (M.I., M.H.). Neuropsychological tests including the Mini-Mental State Examination, brain MR imaging, and SPECT were used for diagnosing dementia. Diagnostic criteria included the following: for $\mathrm{AD}$, criteria from the National Institute of Neurological and Communicative Disorders and StrokeAlzheimer Disease and Related Disorders Association ${ }^{12}$; for vascular dementia, criteria from the National Institute of Neurological Disorders and Stroke-Association Internationale pour la Recherche et l'Enseignement en Neurosciences ${ }^{13}$; for mild cognitive impairment (MCI), general criteria from the International Working Group on Mild Cognitive Impairment ${ }^{14}$; for dementia with Lewy bodies (DLB), clinical criteria from the Consortium on Dementia with Lewy Bodies $^{15}$; and for frontotemporal lobar dementia, the Lund-Manchester criteria for behavioral variant frontotemporal lobar dementia, semantic dementia, or progressive nonfluent aphasia. ${ }^{16}$ If results of all clinical investigations were normal, patients were classified in a subgroup labeled "subjective memory symptoms."

\section{MR Imaging Protocol}

MR imaging was performed with a 3T whole-body system (Magnetom Trio; Siemens, Erlangen, Germany). Axial SWI, axial FLAIR, axial T2-weighted turbo spin-echo sequences, 3D T1weighted magnetization-prepared rapid acquisition of gradient echo sequences, diffusion-weighted imaging, MR spectroscopy, and MRA were performed by using the same section thickness, matrix, and parameters as described previously. ${ }^{11}$

\section{Evaluation of cSS and Other Radiologic Data}

We defined cSS as linear hypointensities on the surface of cerebral cortex gyri on SWI; cSS related to previous symptomatic subarachnoid hemorrhage, traumatic subdural hematoma, or intracranial surgery was not included. cSS was classified as focal (restricted to 3 sulci) or disseminated ( $\geq 4$ sulci).

We defined MBs as small ( $<10 \mathrm{~mm}$ in diameter), homogeneous, round foci of low signal intensity. We excluded symmetric hypointensities in the globi pallidi and dentate nuclei, which we identified as physiologic calcifications or iron deposits; we also excluded hypointense signals inside a lesion that were consistent with infarcts. Lacunar infarcts and white matter hyperintensities were defined according to criteria reported previously. ${ }^{11,17,18}$ The distribution of MBs was categorized as lobar (frontal, temporal, parietal, and occipital) or deep (thalamoganglionic, brain stem, and cerebellum).

Patients with MBs were divided into 3 groups according to the microbleed distribution. The strictly lobar group had MBs localized exclusively in the lobar region. The strictly deep group had MBs located only in the thalamoganglionic and infratentorial regions. The mixed group had MBs throughout both lobar and deep regions. All radiologic findings were assessed by 2 experienced neuroradiologists (H.U., T.H.) who were blinded to the clinical information.

\section{Clinical Data Collection}

Baseline clinical information, including age, sex, history of hypertension, length of education, and Mini-Mental State Examination results, was recorded at registration. Hypertension was defined as a history of hypertension or prescription of antihypertensive medications.

\section{Statistical Analyses}

We compared baseline demographics and clinical characteristics for patients with any cSS and patients with no cSS. Categoric data were evaluated by using the $\chi^{2}$ test and the Fisher 2-tailed exact test. Continuous variables were compared by using the MannWhitney $U$ test. We next conducted multivariate logistic regression analysis to investigate the predictors for diagnosing AD. The independent variables included age, sex, hypertension, length of education, distribution of MBs (strictly lobar, strictly deep, or mixed), lacunar infarcts, white matter hyperintensities, and cSS. Backward stepwise logistic regression analysis was performed by adjusting for age ${ }^{19-21} \mathrm{sex},{ }^{22}$ length of education, ${ }^{23}$ and variables that were automatically selected in a backward stepwise selection method. We performed a backward selection procedure for each outcome by using $P>.10$ of the likelihood ratio test for exclusion of variables. The OR and $95 \%$ CI were obtained. The statistical significance level was set at $P<.05$. In addition, we calculated the sensitivity, specificity, positive predictive value, and negative predictive value of cSS for the clinical diagnosis of AD. Statistical analyses were performed by using JMP 9.0 statistical software (SAS Institute, Cary, North Carolina).

\section{RESULTS}

\section{Prevalence of cSS}

A total of 347 patients (217 women, 130 men; mean age, $74 \pm 9$ years) with cognitive impairment visited our hospital from January 2008 to February 2010. Of these patients, 12 (3.5\%) had cSS.

\section{Clinical Characteristics Related to cSS}

Table 1 provides demographic and clinical characteristics of the patients. Patients with cSS were older $(P=.026)$ compared with patients without cSS. No significant differences were observed in the occurrence of cSS across different types of dementia $(P=$ $.337)$, and a bivariate analysis also demonstrated no differences between patients with and without $\operatorname{AD}(P=.239)$. Sensitivity, specificity, positive predictive value, and negative predictive value of cSS for the clinical diagnosis of AD were 4.9\%, 97.8\%, 66.7\%, and $54.0 \%$, respectively ( 4 patients had cSS but no $\mathrm{AD}, 8$ patients had both cSS and AD, 181 patients had no cSS or AD, and 154 patients had AD but no cSS). 
Table 1: Demographic and clinical characteristics of patients with or without cSS

\begin{tabular}{lcccc}
\hline & \multicolumn{3}{c}{ No. of Patients (\%) } & \\
\cline { 2 - 4 } \multicolumn{1}{c}{ Parameter } & Total & Any cSS & No cSS & P Value \\
\hline No. of patients & 347 & 12 & 335 & \\
Age (yr) (mean) & $74 \pm 9$ & $79 \pm 5$ & $74 \pm 9$ & .026 \\
$\begin{array}{l}\text { No. of women } \\
\text { No. of patients with }\end{array}$ & $217(62.5 \%)$ & $6(50.0 \%)$ & $211(63.0 \%)$ & .361 \\
$\quad 160(46.1 \%)$ & $9(75.0 \%)$ & $151(45.1 \%)$ & .073 \\
hypertension & & & & \\
Length of education & $11(9-12)$ & $11(9-13)$ & $11(9-12)$ & .506 \\
$\quad$ (yr) (mean) (range) & & & & \\
MMSE (mean) & $21 \pm 5$ & $19 \pm 7$ & $21 \pm 5$ & .457 \\
Types of dementia & & & & .337 \\
AD & $162(46.7 \%)$ & $8(66.7 \%)$ & $154(46.0 \%)$ & \\
DLB & $41(11.8 \%)$ & $1(8.3 \%)$ & $40(11.9 \%)$ & \\
FTLD & $33(9.5 \%)$ & $0(0 \%)$ & $33(9.9 \%)$ & \\
VaD & $28(8.1 \%)$ & $1(8.3 \%)$ & $27(8.1 \%)$ & \\
MCI & $51(14.7 \%)$ & $2(16.7 \%)$ & $49(14.6 \%)$ & \\
SC & $32(9.2 \%)$ & $0(0 \%)$ & $32(9.6 \%)$ & \\
\hline
\end{tabular}

Note:-MMSE indicates Mini-Mental State Examination; FTLD, frontotemporal lobar dementia; VaD, vascular dementia; SC, subjective symptoms.

Table 2: Radiologic characteristics of patients with or without cSS

\begin{tabular}{lcccc}
\multicolumn{1}{c}{ Type of MBs } & \multicolumn{3}{c}{ No. of Patients (\%) } & \\
\cline { 2 - 4 } No. of patients & Total & Any cSs & No cSs & P Value \\
Lobar MBs & 347 & 12 & 335 & \\
$\quad$ Frontal & $69(19.9 \%)$ & $7(58.3 \%)$ & $62(18.5 \%)$ & .003 \\
Temporal & $65(18.7 \%)$ & $8(66.7 \%)$ & $57(17.0 \%)$ & $<.001$ \\
Parietal & $78(22.5 \%)$ & $7(58.3 \%)$ & $71(21.2 \%)$ & .007 \\
Occipital & $63(18.2 \%)$ & $7(58.3 \%)$ & $56(16.7 \%)$ & .002 \\
Deep MBs & & & & \\
Thalamoganglionic & $62(17.9 \%)$ & $3(25.0 \%)$ & $59(17.6 \%)$ & .456 \\
Brain stem & $32(9.2 \%)$ & $3(25.0 \%)$ & $29(8.7 \%)$ & .088 \\
Cerebellum & $48(13.8 \%)$ & $3(25.0 \%)$ & $45(13.4 \%)$ & .222 \\
Topographic distribution & & & & \\
of MBs & & & & .020 \\
Strictly lobar & $71(20.5 \%)$ & $6(50.0 \%)$ & $65(19.4 \%)$ & 1.00 \\
Strictly deep & $10(2.9 \%)$ & $0(0 \%)$ & $10(3.0 \%)$ & .154 \\
Mixed & $79(22.8 \%)$ & $5(41.7 \%)$ & $74(22.1 \%)$ & .002 \\
No MBs & $187(53.9 \%)$ & $1(8.3 \%)$ & $186(55.5 \%)$ & .020 \\
Lacunar infarcts & $71(20.5 \%)$ & $6(50.0 \%)$ & $65(19.4 \%)$ & .053 \\
WMH (mean) ${ }^{2}$ & $1.5 \pm 0.8$ & $1.9 \pm 0.8$ & $1.4 \pm 0.8$ & \\
0 & $32(9.2 \%)$ & $0(0 \%)$ & $32(9.6 \%)$ & \\
1 & $166(47.8 \%)$ & $4(33.3 \%)$ & $162(48.4 \%)$ & \\
2 & $107(30.8 \%)$ & $5(41.7 \%)$ & $102(30.4 \%)$ & \\
3 & $42(12.1 \%)$ & $3(25.0 \%)$ & $39(11.6 \%)$ & \\
\hline
\end{tabular}

Note:-WMH indicates white matter hyperintensities.

${ }^{a}$ WMH were graded according to the scale of Fazekas et al ${ }^{17}: 0$, absent; 1 , punctate; 2 , early confluent; and 3, confluent.

\section{Location and Topographic Distribution of MBs}

Strictly lobar MBs were observed more frequently in patients with cSS than in patients without cSS $(P=.020)$, whereas the 2 groups did not differ with regard to the occurrence of strictly deep MBs $(P=1.00)$ and mixed MBs $(P=.154)$. MBs in each cerebral lobe (frontal $[P=.003]$, temporal $[P<.001]$, parietal $[P=.007]$, and occipital $[P=.002])$ had a significant association with the presence of cSS. However, patients with cSS and those without cSS showed no significant differences in the presence of thalamoganglionic $\operatorname{MBs}(P=.456)$, brain stem MBs $(P=.088)$, and cerebellar MBs $(P=.222)$ (Table 2$)$. We also performed a separate analysis of demographic and clinicoradiologic characteristics in patients with $\mathrm{AD}$ and found similar tendencies in location and topographic distribution of MBs for that whole population (On-line Table). Among patients with $\mathrm{AD}$, strictly lobar MBs were ob- served more frequently in patients with cSS than in patients without cSS $(P=$ .004). MBs in each cerebral lobe (frontal $[P=.040]$, temporal $[P<.001]$, parietal $[P=.040]$, and occipital $[P=.006])$ also had a significant association with the presence of cSS.

\section{Clinicoradiologic Characteristics of Patients with cSS}

We further investigated the clinicoradiologic characteristics of 12 patients with cSS ( 6 women, 6 men; mean age, $79 \pm 5$ years) (Table 3$)$. Of these, AD was diagnosed in 8 patients $(66.7 \%)$; DLB, in 1 patient $(8.3 \%)$; vascular dementia, in 1 patient $(8.3 \%)$; and MCI, in 2 patients (16.7\%). cSS was observed in 22 cerebral lobes, and its location corresponded to locations of MBs in 13 lobes (72.2\%). We noted a tendency of cSS to occur in temporal and occipital lobes, and the distribution was focal in 7 patients (58.3\%) and disseminated in 5 patients (41.7\%). Six patients (50\%) had strictly lobar MBs, 5 patients (41.7\%) had mixed MBs, no patient with cSS had strictly deep MBs, and 1 patient $(8.3 \%)$ had no MBs (case 2, Table 3). Four patients $(33.3 \%)$ were classified as having grade 1 white matter hyperintensities; 5 patients $(41.7 \%)$, grade 2 white matter hyperintensities; and 3 patients $(25.0 \%)$, grade 3 white matter hyperintensities. No correlations between age-related white matter change rating scores and the location of cSS were found.

\section{Relationship among cSS, MBs, and $A D$}

Table 4 shows the results of multivariate logistic regression analysis for the diagnosis of $\mathrm{AD}$. In the multivariate model, lacunar infarcts (OR, 0.46; 95\% CI, 0.25-0.81; $P=.007)$ were negatively and independently associated with $\mathrm{AD}$, and the presence of cSS was not associated with $\mathrm{AD}(\mathrm{OR}, 2.99 ; 95 \% \mathrm{CI}, 0.88-12.0 ; P=.08)$.

\section{DISCUSSION}

This study is the first to investigate the diagnostic significance of cSS for AD and the relationships between cSS and the location of MBs in patients with cognitive impairment. The major new finding was that patients with cSS had strictly lobar MBs significantly more often than patients without cSS.

With respect to spatial distributions of MBs, past histopathologic studies of patients with intracerebral hemorrhage revealed that strictly lobar MBs strongly suggested CAA. ${ }^{24}$ The population-based Rotterdam Scan Study showed a tendency for MBs to be located in the lobar region, especially in the temporal lobes. ${ }^{25} \mathrm{~A}$ 


\begin{tabular}{|c|c|c|c|c|c|c|c|c|c|c|c|c|c|}
\hline \multirow[b]{2}{*}{$\begin{array}{c}\text { Subject } \\
\text { No. }\end{array}$} & \multirow[b]{2}{*}{$\begin{array}{l}\text { Type of } \\
\text { Dementia }\end{array}$} & \multirow[b]{2}{*}{$\begin{array}{l}\text { Age } \\
\text { (yr) }\end{array}$} & \multirow[b]{2}{*}{ Sex } & \multirow[b]{2}{*}{$\begin{array}{l}\text { Location } \\
\text { of cSS }\end{array}$} & \multirow[b]{2}{*}{ Frontal } & \multirow[b]{2}{*}{ Temporal } & \multirow[b]{2}{*}{ Parietal } & \multirow[b]{2}{*}{ Occipital } & \multirow{2}{*}{$\begin{array}{c}\text { Topographic } \\
\text { Distribution } \\
\text { of } \mathrm{MBs}\end{array}$} & \multirow[b]{2}{*}{$\mathrm{WMH}^{\mathrm{a}}$} & \multicolumn{3}{|c|}{$\begin{array}{l}\text { ARWMC Rating } \\
\text { Scale }^{\text {b }}(\mathrm{R} / \mathrm{L})\end{array}$} \\
\hline & & & & & & & & & & & Frontal & Temporal & $\begin{array}{l}\text { Parieto- } \\
\text { Occipital }\end{array}$ \\
\hline 1 & $A D$ & 79 & $M$ & Right frontal & - & - & + & + & Mixed & 1 & $1 / 1$ & $1 / 0$ & $1 / 1$ \\
\hline 2 & $A D$ & 81 & $\mathrm{~F}$ & $\begin{array}{l}\text { Left occipital } \\
\text { Right occipital }\end{array}$ & - & - & - & - & No MBs & 2 & $1 / 0$ & $2 / 2$ & $2 / 2$ \\
\hline 3 & $A D$ & 84 & $M$ & Left temporal & - & + & - & - & Strictly lobar & 3 & $2 / 2$ & $3 / 3$ & $2 / 1$ \\
\hline 4 & $A D$ & 83 & $\mathrm{~F}$ & Left temporal & + & + & - & - & Strictly lobar & 2 & $2 / 2$ & $2 / 2$ & $2 / 2$ \\
\hline 5 & $A D$ & 78 & $\mathrm{~F}$ & Right temporal & - & + & + & + & Strictly lobar & 1 & $0 / 0$ & $1 / 1$ & $0 / 0$ \\
\hline 6 & $A D$ & 80 & $M$ & $\begin{array}{l}\text { Right frontal } \\
\text { Right temporal }\end{array}$ & + & + & + & + & Strictly lobar & 2 & $2 / 2$ & $2 / 2$ & $2 / 2$ \\
\hline 7 & $A D$ & 78 & $\mathrm{~F}$ & $\begin{array}{l}\text { Right frontal } \\
\text { Right temporal }\end{array}$ & + & + & + & + & Strictly lobar & 1 & $0 / 1$ & $1 / 0$ & $1 / 1$ \\
\hline 8 & $A D$ & 70 & $\mathrm{~F}$ & $\begin{array}{l}\text { Right parietal } \\
\text { Right occipital }\end{array}$ & + & + & - & + & Strictly lobar & 1 & $1 / 1$ & $1 / 1$ & $1 / 1$ \\
\hline 9 & DLB & 69 & $\mathrm{~F}$ & $\begin{array}{l}\text { Right frontal } \\
\text { Right temporal }\end{array}$ & + & - & + & - & Mixed & 2 & $2 / 2$ & $2 / 2$ & $2 / 2$ \\
\hline 10 & $\mathrm{VaD}$ & 87 & $M$ & $\begin{array}{l}\text { Right frontal } \\
\text { Right temporal } \\
\text { Right occipital } \\
\text { Left temporal } \\
\text { Left occipital }\end{array}$ & + & + & - & + & Mixed & 2 & $1 / 1$ & $2 / 2$ & $2 / 2$ \\
\hline 11 & $\mathrm{MCl}$ & 82 & $M$ & $\begin{array}{l}\text { Right occipital } \\
\text { Left occipital }\end{array}$ & - & - & + & - & Mixed & 3 & $3 / 3$ & $3 / 2$ & $3 / 3$ \\
\hline 12 & $\mathrm{MCl}$ & 80 & $M$ & Left temporal & + & + & + & + & Mixed & 3 & $3 / 3$ & $3 / 3$ & $3 / 3$ \\
\hline
\end{tabular}

Note:-ARWMC indicates age-related white matter changes; R/L, right/left; WMH, white matter hyperintensities; VaD, vascular dementia.

${ }^{a}$ WMH were graded according to the scale of Fazekas et $\mathrm{al}^{17}: 0$, absent; 1 , punctate; 2 , early confluent; and 3, confluent.

${ }^{\mathrm{b}}$ ARWMC rating scale ${ }^{18}: 0$, no lesions (including symmetric, well-defined caps, or bands); 1, focal lesions; 2 , beginning confluence of lesions; 3 , diffuse involvement of the entire region, with or without involvement of $U$ fibers.

Table 4: Multivariate logistic regression analysis for $A D^{a}$

\begin{tabular}{lcc}
\hline \multicolumn{1}{c}{ Parameter } & OR $(95 \%$ CI) & $P$ Value \\
\hline Age (per 1-yr increase) & $0.99(0.96-1.02)$ & .400 \\
Female sex & $0.88(0.55-1.41)$ & .593 \\
Education (per 1-yr increase) & $1.72(0.43-7.02)$ & .448 \\
Lacunar infarcts & $0.46(0.25-0.81)$ & .007 \\
cSS & $2.99(0.88-12.0)$ & .080 \\
\hline
\end{tabular}

${ }^{a}$ The model was adjusted for age, sex, length of education, and variables that showed a relationship to $A D$ in a backward stepwise selection method.

case-control and memory clinic-based cross-sectional study including patients with $\mathrm{AD}$ showed that the microbleed topography was significantly predominant in the occipital region. ${ }^{26}$ Our study indicated that strictly lobar MBs are closely related to cSS, which was shown to be a marker of CAA. This tendency also persisted among patients with $\mathrm{AD}$ with or without cSS, 2 groups who were barely distinguishable from each other except for a higher prevalence of a lobar microbleed location in patients with AD and cSS.

With respect to the diagnostic significance of cSS for $\mathrm{AD}$, though $\mathrm{AD}$ was diagnosed in most patients with cSS, multivariate logistic regression analysis showed that neither cSS nor MBs in any location were independent significant predictors for the diagnosis of $\mathrm{AD}$. An explanation of this result is that CAA pathogenesis also occurs in patients with dementias other than AD. Other histopathologic studies reported CAA in patients with DLB and vascular dementia and a low prevalence of CAA in patients with frontotemporal lobar dementia. ${ }^{27-29}$ MCI was reportedly a transitional state of $\mathrm{AD},{ }^{30}$ so our patients with cognitive impairment may have had CAA pathologic features. Thus, the similar occurrence of cSS and pathologic findings of CAA in patients with cognitive impairment again indicated the same underlying pathophysiologic mechanisms.
As an interesting finding, 1 female patient had $\mathrm{AD}$ and cSS without MBs in the present study, whereas all other patients manifested both cSS and MBs. As with convexity subarachnoid hemorrhage, cSS has causes other than CAA: posterior reversible leukoencephalopathy syndrome, reversible cerebral vasoconstriction syndrome, and lupus vasculitis. ${ }^{31}$ One study indicated that cSS or convexity subarachnoid hemorrhage does not always reflect CAA pathogenesis. ${ }^{31}$ Given the older age and impaired cognition of our patients, however, most cSS in our study presumably resulted from CAA, as in another study that found CAA in $>80 \%$ of patients with $\mathrm{AD} .^{32} \mathrm{~A}$ cross-sectional study including patients with probable or definite CAA, diagnosed on the basis of the Boston criteria, ${ }^{33}$ found inverse associations among the severity of cSS, number of MBs, and apolipoprotein E $\varepsilon 4 .{ }^{34}$ These authors also speculated that cSS may arise from vasculopathic mechanisms different from those associated with CAA-related microbleeds. ${ }^{34}$ Because this patient in our study had no history of possible underlying causes of cSS other than CAA, cSS may have manifested as an initial radiologic finding of CAA.

Limitations of the present study included using a relatively small population and a heterogeneous patient population without $\mathrm{AD}$ (DLB, frontotemporal lobar dementia, vascular dementia, MCI, and subjective symptoms) as a reference group in the multivariate logistic regression analysis.

Our study results indicated that cSS was associated with a lobar location of MBs and may be an initial radiologic finding of CAA in patients with cognitive impairment. Additional prospective studies to investigate temporal changes of these CAA-related MR imaging findings may help in understanding the mechanisms of cognitive decline. 


\section{CONCLUSIONS}

The prevalence of cSS was 3.9\% in our memory clinic. Most patients with cSS were diagnosed as having $\mathrm{AD}$, and the specificity of cSS for the clinical diagnosis of AD was high. Strictly lobar MBs were observed more frequently in patients with cSS than in patients without cSS.

Disclosures: Mitsuharu Ueda-UNRELATED: Grants/Grants Pending: Grants-in-Aid for Science Research from the Ministry of Education, Culture, Sports, Science and Technology of Japan (No. 25870541).* Manabu lkeda_UNRELATED: Grants/Grants Pending: Daiichi Sankyo, ${ }^{*}$ Eisai, ${ }^{*}$ FUJIFILM RI, Janssen Pharmaceuticals, ${ }^{*}$ Nihon MediPhysics, ${ }^{\star}$ Novartis, ${ }^{*}$ Pfizer, ${ }^{*}$ Takeda, ${ }^{*}$ Tsumura, ${ }^{*}$ Comments: as the chairman of the department; Payment for Lectures (including service on Speakers Bureaus): Daiichi Sankyo, Eisai, FUJIFILM RI, Janssen Pharmaceuticals, Nihon Medi-Physics, Novartis, Pfizer, Takeda, Tsumura, MSD, Ono Pharmaceutical. *Money paid to the institution.

\section{REFERENCES}

1. Kumar N. Neuroimaging in superficial siderosis: an in-depth look. AJNR Am J Neuroradiol 2010;31:5-14 CrossRef Medline

2. Linn J, Herms J, Dichgans M, et al. Subarachnoid hemosiderosis and superficial cortical hemosiderosis in cerebral amyloid angiopathy. AJNR Am J Neuroradiol 2008;29:184-86 CrossRef Medline

3. Feldman HH, Maia LF, Mackenzie IR, et al. Superficial siderosis: a potential diagnostic marker of cerebral amyloid angiopathy in Alzheimer disease. Stroke 2008;39:2894-97 CrossRef Medline

4. Linn J, Wollenweber FA, Lummel N, et al. Superficial siderosis is a warning sign for future intracranial hemorrhage. J Neurol 2013;260: 176-81 CrossRef Medline

5. Charidimou A, Peeters AP, Jäger R, et al. Cortical superficial siderosis and intracerebral hemorrhage risk in cerebral amyloid angiopathy. Neurology 2013;81:1666-73 CrossRef Medline

6. Zonneveld HI, Goos JD, Wattjes MP, et al. Prevalence of cortical superficial siderosis in a memory clinic population. Neurology 2014; 82:698-704 CrossRef Medline

7. Wollenweber FA, Buerger K, Mueller C, et al. Prevalence of cortical superficial siderosis in patients with cognitive impairment. J Neurol 2014;261:277-82 CrossRef Medline

8. Charidimou A, Gang Q, Werring DJ. Sporadic cerebral amyloid angiopathy revisited: recent insights into pathophysiology and clinical spectrum. J Neurol Neurosurg Psychiatry 2012;83:124-37 CrossRef Medline

9. Ellis RJ, Olichney JM, Thal LJ, et al. Cerebral amyloid angiopathy in brains of patients with Alzheimer's disease: the CERAD experience, part XV. Neurology 1996;46:1592-96 CrossRef Medline

10. Yamada M. Risk factors for cerebral amyloid angiopathy in the elderly. Ann N Y Acad Sci 2002;977:37-44 CrossRef Medline

11. Uetani H, Hirai T, Hashimoto M, et al. Prevalence and topography of small hypointense foci suggesting microbleeds on $3 \mathrm{~T}$ susceptibility-weighted imaging in various types of dementia. AJNR Am J Neuroradiol 2013;34:984-89 CrossRef Medline

12. McKhann G, Drachman D, Folstein M, et al. Clinical diagnosis of Alzheimer's disease: report of the NINCDS-ADRDA Work Group under the auspices of Department of Health and Human Services Task Force on Alzheimer's Disease. Neurology 1984;34:939-44 CrossRef Medline

13. Román GC, Tatemichi TK, Erkinjuntti T, et al. Vascular dementia: diagnostic criteria for research studies-report of the NINDSAIREN International Workshop. Neurology 1993;43:250-60 CrossRef Medline

14. Winblad B, Palmer K, Kivipelto M, et al. Mild cognitive impairment beyond controversies- towards a consensus: report of the International Working Group on Mild Cognitive Impairment. J Intern Med 2004;256:240 - 46 CrossRef Medline

15. McKeith IG, Galasko D, Kosaka K, et al. Consensus guidelines for the clinical and pathologic diagnosis of dementia with Lewy bodies
(DLB): report of the consortium on DLB international workshop. Neurology 1996;47:1113-24 CrossRef Medline

16. Neary D, Snowden JS, Gustafson L, et al. Frontotemporal lobar degeneration: a consensus on clinical diagnostic criteria. Neurology 1998;51:1546-54 CrossRef Medline

17. Fazekas F, Chawluk JB, Alavi A, et al. MR signal abnormalities at $\mathbf{1 . 5}$ T in Alzheimer's dementia and normal aging. AJR Am J Roentgenol 1987;149:351-56 CrossRef Medline

18. Wahlund LO, Barkhof F, Fazekas F, et al; European Task Force on Age-Related White Matter Changes. A new rating scale for age-related white matter changes applicable to MRI and CT. Stroke 2001; 32:1318-22 CrossRef Medline

19. Evans DA, Funkenstein HH, Albert MS, et al. Prevalence of Alzheimer's disease in a community population of older persons: higher than previously reported. JAMA 1989;262:2551-56 CrossRef Medline

20. Jorm AF, Korten AE, Henderson AS. The prevalence of dementia: a quantitative integration of the literature. Acta Psychiatr Scand 1987; 76:465-79 CrossRef Medline

21. Rocca WA, Amaducci LA, Schoenberg BS. Epidemiology of clinically diagnosed Alzheimer's disease. Ann Neurol 1986;19:415-24 CrossRef Medline

22. Gao S, Hendrie HC, Hall KS, et al. The relationships between age, sex, and the incidence of dementia and Alzheimer disease: a metaanalysis. Arch Gen Psychiatry 1998;55:809-15 CrossRef Medline

23. Lindsay J, Laurin D, Verreault R, et al. Risk factors for Alzheimer's disease: a prospective analysis from the Canadian Study of Health and Aging. Am J Epidemiol 2002;156:445-53 CrossRef Medline

24. Fazekas F, Kleinert R, Roob G, et al. Histopathologic analysis of foci of signal loss on gradient-echo $\mathrm{T} 2^{\star}$-weighted MR images in patients with spontaneous intracerebral hemorrhage: evidence of microangiopathy-related microbleeds. AJNR Am J Neuroradiol 1999;20: 637-42 Medline

25. Mesker DJ, Poels MM, Ikram MA, et al. Lobar distribution of cerebral microbleeds: the Rotterdam Scan Study. Arch Neurol 2011;68: 656-59 CrossRef Medline

26. Shams S, Martola J, Granberg T, et al. Cerebral microbleeds: different prevalence, topography, and risk factors depending on dementia diagnosis-the Karolinska Imaging Dementia Study. AJNR Am J Neuroradiol 2015;36:661-66 CrossRef Medline

27. Esiri MM, Wilcock GK. Cerebral amyloid angiopathy in dementia and old age. J Neurol Neurosurg Psychiatry 1986;49:1221-26 CrossRef Medline

28. De Reuck J, Deramecourt V, Cordonnier C, et al. Prevalence of small cerebral bleeds in patients with a neurodegenerative dementia: a neuropathological study. J Neurol Sci 2011;300:63-66 CrossRef Medline

29. De Reuck J, Deramecourt V, Cordonnier C, et al. Detection of microbleeds in post-mortem brains of patients with frontotemporal lobar degeneration: a 7.0-Tesla magnetic resonance imaging study with neuropathological correlates. Eur J Neurol 2012;19:1355-60 CrossRef Medline

30. Markesbery WR. Neuropathologic alterations in mild cognitive impairment: a review. J Alzheimers Dis 2010;19:221-28 CrossRef Medline

31. Kumar S, Goddeau RP Jr, Selim MH, et al. Atraumatic convexal subarachnoid hemorrhage: clinical presentation, imaging patterns, and etiologies. Neurology 2010;74:893-99 CrossRef Medline

32. Pettersen JA, Sathiyamoorthy G, Gao FQ, et al. Microbleed topography, leukoaraiosis, and cognition in probable Alzheimer disease from the Sunnybrook dementia study. Arch Neurol 2008;65:790-95 CrossRef Medline

33. Knudsen KA, Rosand J, Karluk D, et al. Clinical diagnosis of cerebral amyloid angiopathy: validation of the Boston criteria. Neurology 2001;56:537-39 CrossRef Medline

34. Shoamanesh A, Martinez-Ramirez S, Oliveira-Filho J, et al. Interrelationship of superficial siderosis and microbleeds in cerebral amyloid angiopathy. Neurology 2014;83:1838-43 CrossRef Medline 